\title{
Editorial: Milk is good for you
}

\author{
Mansel W Griffiths* \\ Canadian Research Institute for Food Safety, University of Guelph, N1G 2W1, Canada
}

As a member of the Executive Editorial Board of the Journal of Dairy Research I have the opportunity to write an editorial highlighting the advances in dairy research documented in this issue of the journal. As with all industries, the dairy industry has embraced major technological change in the last four decades; from the introduction of robotic milking to the development of dairy foods with targeted health benefits. The opportunities for the latter are only limited by our imagination. The advances in genetic engineering have made it possible to, for instance, produce bovine milk that has greater similarity to human milk as well as being hypoallergenic. These trends in 'engineered milk products' are reviewed by Chandrapaula and Zisu in this issue of the journal (Chandrapala \& Zisu, 2016). As we learn more about how the gut microbiome influences human health, including mental health, then we can further modify dairy products to beneficially alter the microbial composition of the gut. This has already been illustrated for ruminants with polyunsaturated fatty acid supplementation of diets giving rise to 'healthier' milk (see for example in this issue, Caroprese et al. 2016).

With regard to human health, the burgeoning market in probiotics, which has been projected to reach nearly $\$ 47$ billion by 2020, has seen the development of numerous dairy products as vehicles for the delivery of these organisms to the gut. The search continues for novel probiotics in unexpected places, including the milk from non-ruminants, such as donkeys (in this issue: Soto del Rio et al. 2016). One of the more important biological consequences resulting from the presence of probiotics in dairy products and the gut is the breakdown of proteins and other compounds into bioactive moieties. The release of encrypted peptides from caseins and whey proteins has several impacts on health as these peptides have antimicrobial, antihypertensive, anti-cancer, anti-virulence and immunomodulatory activities, among others. For example, water soluble peptides obtained from Greek yoghurt modulate the expression of genes involved in the synthesis of the urokinase-plasminogen activator, which influences inflammatory and immune responses (Theodorou \& Politis, 2016). Optimisation of the production of these peptides will allow the development of more functional dairy products using material such as cheese whey (see in this issue; Rodriguez-Pazo et al. 2016).
However, not only probiotics but the components of milk itself can have desirable health outcomes. As well as the more commonly known benefits of drinking milk such as it being an excellent source of calcium, there are emerging nutritional advantages to the consumption of milk and dairy products, such as increased satiety, which may help combat obesity, and it has been shown that components of the milk fat globule membrane may reduce cancer cell proliferation. There is also increasing evidence that dairy product consumption can alleviate the consequences of metabolic syndrome, such as type 2 diabetes. Indeed, in the current issue of the journal, Meena et al. (2016) present evidence that camel milk and, to a lesser extent, goats' milk can help reduce hyperglycaemia and oxidative damage resulting from type- 1 diabetes.

There is no doubt that milk is good for you. As we learn more about the mechanisms involved in the health benefits of consuming dairy products, the opportunities to 'design' healthier foods through the modification of milk components or the addition of fermentative cultures become endless. This will ensure the sustainability and profitability of the dairy industry, in all its forms, for many decades to come.

\section{References}

Caroprese M, Ciliberti MG, Marino R, Santillo A, Sevi A \& Albenzio M (2016) Polyunsaturated fatty acid supplementation: effects of seaweed Aschophyllum nodosum and flaxseed on milk production and fatty acid profile of lactating ewes during summer Journal of Dairy Research 83 289-297

Chandrapala J \& Zisu B (2016) Novel trends in engineered milk products Journal of Dairy Research 83 268-280

Meena S, Rajput YS, Pandey AK, Sharma R \& Singh R (2016) Camel milk ameliorates hyperglycemia and oxidative damage in type-1 diabetic experimental rats Journal of Dairy Research 83 412-419

Rodríguez-Pazo N, da Silva Sabo S, Salgado-Seara JM, Al Arni S, de Souza Oliveira RP \& Domínguez JM (2016) Optimisation of cheese whey enzymatic hydrolysis and further continuous production of antimicrobial extracts by Lactobacillus plantarum CECT-221 Journal of Dairy Research 83 402-411

Soto del Rio MLD, Andrighetto C, Dalmasso A, Lombardi A, Civera T \& Bottero MT (2016) Isolation and characterization of lactic acid bacteria from donkey milk Journal of Dairy Research 83 383-386

Theodorou G \& Politis I (2016) Leukocyte expression of genes implicated in the plasminogen activation cascade is modulated by yoghurt peptides Journal of Dairy Research 83 360-365 